\title{
Progress towards the control and management of the thalassemias
}

Suthat Fucharoen $\mathrm{MD}^{1^{*}}$, David J. Weatherall MD FRCP FRS ${ }^{2}$

${ }^{1}$ Thalassemia Research Center, Institute of Molecular Biosciences, Mahidol University, Nakornpathom, Thailand (suthat.fuc@mahidol.ac.th); ${ }^{2}$ Weatherall Institute of Molecular Medicine, John Radcliffe Hospital, University of Oxford, Oxford, UK (liz.rose@imm.ox.ac.uk). *Corresponding author

\section{Disclosure statement}

The authors have nothing to disclose.

\section{Key Words}

Different forms of thalassemia. Screening. Prevention. Management. National Partnerships. Role of non-governmental organizations.

\section{Key Points}

The prevention and management of the thalassemias is reasonably advanced in several countries in Asia.

Partnerships are being developed between these countries and those in which facilities for the control and development of thalassemia are not yet established.

There is urgent need for support on behalf of international health agencies for the further development of these programs. 


\section{Synopsis}

Because of the particular high frequency of different severe forms of both $\alpha$ and $\beta$ thalassemia in Asia the development of approaches for their prevention and management is particularly challenging. However, because of earlier partnerships with richer countries, so-called North/South partnerships, and help from their governments, considerable progress towards the better control of the thalassemias has been achieved in some countries. There is growing evidence that these countries are now starting to form partnerships with those where there are very limited facilities for the control and management of the thalassemias, so-called South/South partnerships. However, because of limited financial resources these partnerships will only be successful in the long term if further support is provided by international health agencies. It is vital therefore that the global health importance of the thalassemias and related disorders, by far the commonest genetic diseases, is emphasized to the appropriate agencies of this type.

\section{Progress of thalassemia control in Thailand}

\section{Thalassemia in Thailand}

Both $\alpha$-thalassemia and $\beta$-thalassemia and some abnormal hemoglobins $(\mathrm{Hb})$, such as $\mathrm{Hb} \mathrm{E}$ and $\mathrm{Hb}$ Constant Spring (CS), are prevalent in Thailand. The frequencies are $20 \%$ to $30 \%$ for $\alpha$-thalassemia, $3 \%$ to $9 \%$ for $\beta$-thalassemia, $10 \%$ to $50 \%$ for $\mathrm{Hb}$ $\mathrm{E}$, and $1 \%$ to $8 \%$ for $\mathrm{Hb} \mathrm{CS}^{1,2}$. Different combinations of these abnormal genes lead to over 60 thalassemia syndromes. The two major alpha thalassemic diseases are $\mathrm{Hb}$ Bart's hydrops fetalis or homozygous $\alpha^{0}$-thalassemia and $\mathrm{Hb} \mathrm{H}$ disease that results from the interaction between $\alpha^{0}$-thalassemia heterozygotes and $\alpha^{+}$ thalassemia or between $\alpha^{0}$-thalassemia and $\mathrm{Hb}$ CS heterozygotes. Almost all $\mathrm{Hb}$ Bart's hydrops fetuses die intra utero or a few minutes after birth and their mothers 
often suffer from obstetric complications such as toxemia of pregnancy (preclampsia and eclampsia), postpartum hemorrhage due to an enlarged placenta, and the psychological burden of carrying a non-viable fetus to term. Interaction between $\beta$ thalassemia genes or $\beta$-thalassemia and $\mathrm{Hb} E$ genes leads to homozygous $\beta$ thalassemia or $\beta$-thalassemia/Hb E disease that are major beta thalassemic syndromes in this region. In $\beta$-thalassemia/Hb E disease, although the patients have identical genotypes, the degree of anemia varies greatly with hemoglobin levels ranging from 3-13 $\mathrm{g} / \mathrm{dl}^{3-5}$. The birth rates of major thalassemic diseases are shown in Table 1.

Since 2002 Thailand has implemented the Universal Health Care (UHC) policy that resulted in a $99 \%$ universal coverage among Thai nationals using a mix of health protection schemes. Under this policy all the Thais will receive free treatment, either at the nearby district hospital or by referral for treatment in a medical center for cases that need special care. Almost all thalassemia patients can access to free blood transfusion, and iron chelation such as desferrioxamine and deferiprone. To reduce the cost of the iron chelators the Government Pharmaceutical Organization has synthesized deferiprone for local use. The product is effective in the treatment of iron overload in all thalassemia syndromes, except thalassemia major cases that need regular blood transfusion that still need desferrioxamine treatment as a combination therapy 6,7 . The estimated direct cost for the management of a thalassemia major patient that receives regular blood transfusion and desferrioxamine treatment who lives for 10-30 years old is about 1.3 to 6.6 millions Baht (US $\$ 39,393-200,000)^{8}$. Even though thalassemia may be cured by stem cell transplantation, however it is still expensive and it is difficult to find appropriate HLA matched donors. Thus the best approaches to cope with thalassemia in developing countries, including Thailand, is to prevent the birth of a new cases with major thalassemic diseases. 


\section{Prevention and Control Program for Thalassemia in Thailand}

A nationwide program has commenced to prevent and control homozygous $\beta$ thalassemia, compound heterozygote $\beta$-thalassemia/Hb E, and $\mathrm{Hb}$ Bart's hydrops fetalis. The program started in 1997, after some preparation in technology transfer to the Minister of Public Health. Three major Departments are involved in this program, namely Department of Medical Services, Department of Health and Department of Medical Sciences. The three departments are involved in the prevention and control of thalassemia as follows. 1) The Department of Medical Services is involved in the improvement of treatment to improve the quality of life of thalassemia patients. The Department has worked in collaboration with the Thalassemia Foundation of Thailand and Thai Hematology Society to develop a Clinical Practice Guideline as a reference for how to manage thalassemia in Thailand. 2) The Department of Health is involved more in the screening, counseling and prenatal diagnosis under the policy "Select partner, Select pregnancy, Select birth" that will lead to thalassemia-free babies born in the kingdom. 3) The Department of Medical Science is involved in the training of laboratory technicians at various levels to learn how to screen for thalassemia carriers and high risk couples by using both simple screening tests and standard procedures for the accurate diagnosis of thalassemia. During 1997 through 2010 we had conducted many workshops and trained medical staff including pediatricians, physicians, nurses, medical technologists and technicians in basic knowledge about thalassemia, laboratory diagnosis and management. Declaration of the nationwide policy by the Permanent Secretary of the Ministry of Public Health for thalassemia control was announced on February 9, 2005 (Table 2). Until today we are still conducting refresher courses and have held a National Annual Meeting on Thalassemia for the last 20 years.

The target group for thalassemia screening is pregnant women. This is done by simple one tube osmotic fragility test for $\beta$ and $\alpha^{0}$-thalassemia carriers and $\mathrm{Hb} \mathrm{E}$ by 
dichlorophenol-indolphenol dye test (DCIP dye test) ${ }^{9}$. The husband of those pregnant women that have a positive screening test will be called up for further screening. The couples that have positive screening of both husband and wife will be further referred for a confirmation test by standard methods of blood counts and hemoglobin analysis by automatic high performance liquid chromatography HPLC (Bio Rad, Variant System) or by capillary zone electrophoresis in some centers ${ }^{10,11 .}$ Figure 1 demonstrates the schematic outline of thalassemia screening in Thailand. The result of nationwide screening for high risk couple shows that it varies from the north to south related to the abnormal gene frequencies in each region (Figure 2). Wanapirak et al, Chiangmai University, has shown that the total cost of screening for high risk couples plus the cost of prenatal diagnosis in 21,975 pregnant women and prevention of the birth of 80 severe thalassemic diseases (both $\alpha$ - and $\beta$ thalassemia) is much cheaper than the costs of treatment of these patients if they were born (Table 3$)^{12}$.

The overall result of thalassemia control program at Chiangmai Medical School is summarized in Table 4A and the result of national screening cases is summarized in Table 4B. After 20 years of launching a nationwide control program for severe thalassemia we still achieve only around $50 \%$ screening of pregnant women because many of them attend the antenatal care clinic late. Moreover, we still have the problem of investigating the husband because some of them work in other places, and even abroad. At the moment we are planning to move further to perform pre-marital screening and non-pregnant women as well.

\section{Thalassemia in other regions of Asia}

Thalassemia is common in almost all Asian countries. $\alpha$-Thalassemia, $\beta$ thalassemia and $\mathrm{Hb} \mathrm{E}$ are commonly noted as the hallmark of Southeast Asia, Sri Lanka, Bangladesh, Maldives and the eastern region of India and south China. 
Hemoglobin CS is also prevalent in the Southeast Asia Region. The most serious form of thalassemia, Hemoglobin Bart's hydrops fetalis, is almost exclusively found in Southeast Asia and south China ${ }^{1,2}$. The frequency of these abnormal genes in Asian countries is summarized in Tables 5A and 5B. However, the capability to cope with this magnitude of a public health problem varies widely (Tables 6, 7). Because of this the Asian Network for Thalassemia Control (ANTC) was established during a conference on Genetics and Population Health held in Fremantle, Australia, 2004. Representatives from a number of Asian countries together with workers in the thalassemia field from the UK, Canada and Australia agreed to work together with Asian people towards the prevention and control of thalassemia in Asia. It was agreed that the ANTC should focus on fact-finding regarding the extent of the problem in individual countries together with an account of the facilities that exist for the diagnosis and management of the different forms of thalassemia in each country. The health burden of the thalassemias in Asia should be translated into disability adjusted life years (DALYs). Using this approach it is possible to compare the health burden of the thalassemias with other health problems in Asia (see Chapter 2). Although the preliminary data indicate that thalassemia will pose a health burden comparable with some of the major communicable diseases, far more data are required, particularly gene frequency and accurate costing of both prevention and treatment regimes. During the last ten years many Asian countries have made progresses in thalassemia.

Guangxi, south China, where thalassemia and $\mathrm{Hb} \mathrm{E}$ is very common launched a prevention program in 2010 . They have set a "one stop service unit" for thalassemia screening at Marriage Registration Centers (in China all couple must be registered at these centers). This is where they educate newly married couples about birth control, HIV, and other issues including thalassemia, after which blood is drawn and sent to the hospital for a test. Those couples who show a positive blood test will be called back for further counseling. In general this is pre-conception counseling 
followed by prenatal diagnosis when they become pregnant. Table 8 shows some preliminary data of the prevention and control program in Guangxi. About $50 \%$ of pregnant women were screened for thalassemia and they can prevent births of severe and intermedia thalassemia in 6,940 cases within five years.

Malaysia started a National Thalassemia Program in 2004 and a year later the Malaysian government provided a 40 million Ringit (US\$ 10.6 million) grant to support the program. This budget is for public awareness \& health education, population screening and laboratory diagnosis, comprehensive management of patients and a thalassemia registry. Up to 2014 the number of patients with thalassemia was as follows: $\beta$-thalassemia major 2415 cases, $\beta$-thalassemia/Hb E 1961 cases, $\beta$-thalassemia intermedia 590 and 359 cases of $\mathrm{Hb} \mathrm{H}$ disease. The method of screening for couples at risk is through cascade screening and is voluntary ${ }^{13}$.

Sri Lanka launched a National Prevention Program in 2006 (see Chapter 14). The aim of the program is 1) drafting guidelines and protocols on prevention and management, 2) support for transferring affordable resources and technologies and 3) promotion of community empowerment and mobilization. The government provided 40 million Rs (US\$298,982) for equipment to the regional thalassaemia screening centers in 2008. Under this program they have screened more than 100,000 individuals; $16.3 \%$ have received a "pink card" that means thalassemia carrier while those who are normal received a "green card" 14 .

Indonesia is preparing for a nationwide thalassemia prevention program. Epidemiologic studies and genotyping to determine the distribution of abnormal hemoglobin genes, including $\alpha$-thalassemia, $\beta$-thalassemia and $\mathrm{Hb} E$ in different islands/ethnic groups has been conducted. This will help to plan an appropriate strategy for a future prevention program in the country. Currently the government provides a budget to buy deferasirox (Exjade) for thalassemia patients with iron 
overload. A clinical practice guideline has been developed. Some pilot models of thalassemia screening have been conducted in several medical centers ${ }^{14}$.

India has also conducted an epidemiologic study for abnormal hemoglobin genes in different part of the country (see Chapter 10). A pilot model for mass screening, genetic counseling has been developed in six centers: Maharashtra, Gujarat, West Bengal, Assam, Karnataka and Punjab. The results show that among the 21,645 cases screened, including 10673 college students and 10972 antenatal cases, the prevalence of $\beta$-thalassemia trait varies from 2 to $4 \%$. The major problem in India is that $50 \%$ of pregnant women first attended hospital in the $3^{\text {rd }}$ trimester ${ }^{14}$.

Even in other Asian countries which do not have a nationwide program for the prevention of thalassemia some progress has been made. Almost all Asian countries have established a non-government society/foundation for parents and patients. This is partly supported by the Thalassemia International Federation (TIF). TIF has also arranged to donate an automatic HPLC system to Cambodia and is planning for the $2^{\text {nd }}$ Pan-Asian Conference on Haemoglobinopathies in Hanoi, Vietnam during 26-27 September 2015 (the $1^{\text {st }}$ Pan-Asian Conference on Haemoglobinopathies was held in Bangkok, February 2012). Although without support from international agencies collaboration between Asian countries is developing. At the moment Thailand is working with their colleagues in Bangladesh, Cambodia, Myanmar, Laos and Vietnam to identify molecular defects of both $\alpha$ and $\beta$-thalassemias and also helping in training technicians and scientists from these countries. It also supports each country to conduct education meetings and workshops on laboratory diagnosis of thalassemia by helping them to organize the program and send speakers to give lectures. August 7-8, 2014 was the first time that Southeast Asian Regional Office of the World Health Organization (SEARO) called for a meeting on management and prevention of thalassemia in the region in New Delhi. The objective of the meeting was to review and learn from the 
experiences of the countries and to review their draft regional guidelines on management and prevention of thalassemia.

\section{Global Issues}

It has been recognized for some time that the thalassemias, like the sickle cell disorders, are producing an increasingly serious global health problem ${ }^{1,15}$. As well as the remarkable diversity of these conditions in Asian countries, particularly the severe forms of $\alpha$ thalassemia as well as $\beta$ thalassemia, the latter occur at variable rates throughout the Middle East, the Mediterranean region and localized parts of Africa. Like some of the Asian countries slow progress has been made in many of these regions towards the prevention and better management of the different forms of thalassemia but, given the remarkable diversity of acquired communicable and other diseases, it has been very difficult for the governments of some of these countries to either recognize or develop programs for the control of the thalassemias.

In 2002 the World Health Organization published a report entitled Genomics and World Health that recommended both North/South and South/South partnerships as an approach to the control and management of common genetic diseases such as the hemoglobin disorders. These recommendations were later confirmed by the World Health Organization Executive Board, and at the 59 ${ }^{\text {th }}$ World Health Assembly resolutions were passed to urge member states to develop programs for the prevention and management of the hemoglobin disorders. Later, a meeting was held under the auspices of the World Health Organization and TIF that published further recommendations for the development of international partnerships of this kind for the control of the hemoglobin disorders ${ }^{16}$. Recently, and for the first time, the inherited hemoglobin disorders have been included in the latest edition of the Global Burden of Disease Program and they have been clearly defined as major factors in the global burden of anemia ${ }^{17,18}$ (see Chapter 2). 
Although there is evidence that the governments of developing countries are slowly becoming aware of the importance of the inherited disorders of hemoglobin progress is still very slow. The World Health Organization and related international bodies have done very little to support the concept of North/South and South/South partnerships and with a few notable exceptions the major international medical funding charities have shown little interest in inherited diseases. It seems likely that this situation will continue unless these bodies can be persuaded to produce more balanced support between inherited and acquired diseases in the future.

An important factor for the future will be work directed at determining the true global burden of the inherited hemoglobin disorders. It is becoming clear that our knowledge of the true frequency of these conditions is still rather limited. There is growing evidence that these conditions vary in their frequency in many countries over short geographical distances and much of the published data is based on measurements of gene frequency in one or two centers which is then extrapolated to the whole country. Hence the true burden of these conditions will only become apparent by detailed micro mapping of their frequency throughout high frequency countries $^{19-21}$.

\section{Conclusion}

Thalassemia is one of the major global public health problems. The strategy for control programs consists of treatment and prevention, i.e. treatment of existing patients in the most cost-benefit way and reducing the birth of new cases. The specific target is to set up the core of effective treatment, prevention and training services in each country. This should define the methods of treatment and prevention appropriate to individual countries. To achieve success in the prevention and control of thalassemia it needs continuity and a holistic approach. It is expected 
that with optimal collaboration between countries in high-frequency regions and north-south collaboration effective prevention and control can be achieved.

\section{Acknowledgement:}

This work was supported by a Research Chair Grant from the National Science and Technology Development Agency (NSTDA) and Mahidol University, Thailand, The Wellcome Trust and Medical Research Council, UK and the Anthony Cerami and Ann Dunne Foundation for World Health.

\section{References}

1. Weatherall DJ, Clegg JB. The Thalassaemia Syndromes (ed 4th). Oxford: Blackwell Science; 2001.

2. Fucharoen $S$, Winichagoon P. Thalassemia in Southeast Asia: problems and strategy for prevention and control. Southeast Asian J of Trop Med Pub Health. 1992;23:647-655.

3. Winichagoon $P$, Thonglairoam $V$, Fucharoen $S$, et al. Severity differences in $\beta$ thalassaemia.haemoglobin $\mathrm{E}$ syndromes: implication of genetic factors. Brit $J$ Haematol. 1993;83:633-639.

4. Sripichai O, Makarasara W, Munkongdee T, et al. A scoring system for the classification of beta-thalassemia/Hb E disease severity. Am $\mathrm{J}$ Hematol. 2008;83:482-484.

5. Premawardhena A, Fisher CA, Olivieri NF, et al. Haemoglobin $E \beta$ thalassaemia in Sri Lanka. Lancet. 2005;366:1467-1470.

6. Viprakasit V, Nuchprayoon I, Chuansumrit A, et al. Deferiprone (GPO-L$\mathrm{ONE}((\mathrm{R}))$ ) monotherapy reduces iron overload in transfusion-dependent thalassemias: 1-year results from a multicenter prospective, single arm, open 
label, dose escalating phase III pediatric study (GPO-L-ONE; A001) from Thailand. Am J Hematol. 2013;88:251-260.

7. Songdej D, Sirachainan N, Wongwerawattanakoon $\mathrm{P}$, et al. Combined chelation therapy with daily oral deferiprone and twice-weekly subcutaneous infusion of desferrioxamine in children with beta-thalassemia: 3-year experience. Acta haematologica. 2015;133:226-236.

8. Leelahavarong $P$, Chaikledkaew $U$, Hongeng $S$, et al. A cost-utility and budget impact analysis of allogeneic hematopoietic stem cell transplantation for severe thalassemic patients in Thailand. BMC health services research. 2010;10:209.

9. Fucharoen G, Sanchaisuriya K, Sae-ung N, et al. A simplified screening strategy for thalassaemia and haemoglobin $E$ in rural communities in southeast Asia. Bull World Health Organ. 2004;82:364-372.

10. Fucharoen $\mathrm{S}$, Winichagoon $\mathrm{P}$, Wisedpanichkij $\mathrm{R}$, et al. Prenatal and postnatal diagnoses of thalassemias and hemoglobinopathies by HPLC. Clin Chem. 1998;44:740-748.

11. Winichagoon $P$, Svasti $S$, Munkongdee $T$, et al. Rapid diagnosis of thalassemias and other hemoglobinopathies by capillary electrophoresis system. Transl Res. 2008;152:178-184.

12. Wanapirak C. Cost-benefit analysis between screening for high risk couples to prevention of birth of severe thalassemia at Chiangmai University Medical School. Proceeding, National Annual Thalassemia Meeting. Kosa Hotel, Khon Kaen; 2002.

13. Hishamshah B. Mohd Ibrahim. Personal communication.

14. SEARO/WHO. Thematic Group Meeting on Management and Prevention of Thalassaemia. Lalit Hotel, New Delhi; 2014.

15. Weatherall DJ. The inherited diseases of hemoglobin are an emerging global health burden. Blood. 2010;115:4331-4336.

16. WHO. Management of Haemoglobin Disorders. Report of a joint WHO-TIF meeting. 16-18 November 2007, Nicosia, Cyprus. World Health Org. 2008. 
17. Kassebaum $\mathrm{NJ}$, Jasrasaria $\mathrm{R}$, Naghavi M, et al. A systematic analysis of global anemia burden from 1990 to 2010. Blood. 2014;123:615-624.

18. Murray CJ, Vos T, Lozano R, et al. Disability-adjusted life years (DALYs) for 291 diseases and injuries in 21 regions, 1990-2010: a systematic analysis for the Global Burden of Disease Study 2010. Lancet. 2012;380:2197-2223.

19. Colah R, Gorakshakar A, Phanasgaonkar S, et al. Epidemiology of betathalassaemia in Western India: Mapping the frequncies and mutations in subregions of Maharashtra and Gujarat. Br J Haematol. 2010;149:739-747.

20. Weatherall DJ. The importance of micromapping the gene frequencies for the common inherited disorders of haemoglobin. Br J Haematol. 2010;149:635637.

21. Weatherall DJ. The challenge of haemoglobinopathies in resource-poor countries. Br J Haematol. 2011;154:736-744. 